\title{
Study on the Stability Principle of Mechanical Structure of Roadway with Composite Roof
}

\author{
Yang Yu ${ }^{1,2}$, Jianfei Lu ${ }^{1, *}$, Dingchao Chen ${ }^{3, *}$, Yuxin Pan ${ }^{1}$, Xiangqian Zhao ${ }^{3}$ and Lianying Zhang ${ }^{1}$ \\ 1 School of Civil Engineering, Xuzhou University of Technology, Xuzhou 221111, China; \\ yuyang@xzit.edu.cn (Y.Y.); 20190702105@xzit.edu.cn (Y.P.); zhanglianying@xzit.edu.cn (L.Z.) \\ 2 Tai'an Fangzhou Mining Technology Co., Ltd., Tai'an 271024, China \\ 3 School of Mining Engineering, China University of Mining and Technology, Xuzhou 221116, China; \\ TS20020080A31@cumt.edu.cn \\ * Correspondence: 20180702121@xzit.edu.cn (J.L.); $20170702129 @ x z i t . e d u . c n$ (D.C.); \\ Tel.: +86-0516-83689920 (J.L.)
}

check for

updates

Citation: Yu, Y.; Lu, J.; Chen, D.; Pan, Y.; Zhao, X.; Zhang, L. Study on the Stability Principle of Mechanical Structure of Roadway with Composite Roof. Minerals 2021, 11, 1003. https://doi.org/10.3390/ $\min 11091003$

Academic Editors: Saiied Aminossadati and Abbas Taheri

Received: 1 August 2021

Accepted: 9 September 2021

Published: 14 September 2021

Publisher's Note: MDPI stays neutral with regard to jurisdictional claims in published maps and institutional affiliations.

Copyright: (c) 2021 by the authors. Licensee MDPI, Basel, Switzerland. This article is an open access article distributed under the terms and conditions of the Creative Commons Attribution (CC BY) license (https:// creativecommons.org/licenses/by/ $4.0 /)$.

\begin{abstract}
With the typical composite roof roadway and roof fall accidents in the Guizhou Province of China as the research background, the expression of damage parameters of composite roof was deduced according to Weibull statistical distribution, generalized Hooke's law and Mises yield criterion, and the influence of shape and scale parameters of Weibull on damage characteristic was discussed. Based on the infinite slab theory, the expressions of deflection and layer separation of each layer of the composite roof were obtained, the critical load expression of each delamination was determined, and the influence of roadway width, overlying strata load, elastic modulus, shape parameters and scale parameters on the stability of composite roof was explored. The research shows that the bolt support can effectively reduce the layer separation between the composite roofs and enhance the stability of the composite roof. On this basis, it is proposed that for the surrounding rock control problem of roadways with composite roof, the active support technology with bolts as the core should be adopted.
\end{abstract}

Keywords: composite roof; mechanical model; bolt support; weibull distribution

\section{Introduction}

China is one of the countries with the most abundant coal resources in the world. According to the survey data, as of 2019, China's total proven coal reserves are about 1758.8 billion tons, ranking the third in the world. The spatial distribution of coal resources in China is characterized by more coal resources in the west and less in the east, more in the north and less in the south. Inner Mongolia, Shanxi, Shaanxi, Xinjiang, and Guizhou are the top five coal producing provinces in China [1-5]. The coal output of each province in China in 2019 is shown in Figure 1.

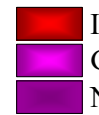

Inner Mongolia $\square$ Shanxi $\square$ Shaanxi $\square$ Xinjiang Guizhou $\square$ Shandong $\square$ Anhui $\square$ Henan Ningxia $\square$ Heilongjiang

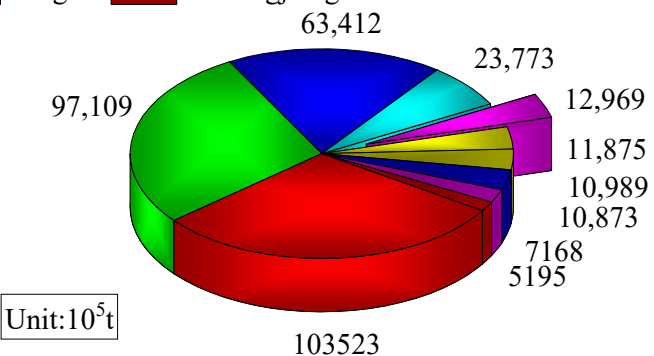

Figure 1. Distribution of China's coal production in 2019. 
Guizhou is a big coal province in southern China, known as the southwest coal sea. Coal resources are rich, coal types are complete and shallow, mainly distributed in the Liuzhi, Panjiang and Shuicheng areas in western Guizhou. However, the mining of coal resources in Guizhou Province generally has the problems of high gas content, complex occurrence conditions, and poor stability of roof and floor, which leads to more small coal mines, extensive production mode, backward production technology, and frequent safety accidents, which is extremely unfavorable to the healthy development of the coal industry in Guizhou Province. The statistics of coal mine accidents in 2019 in Guizhou Province are shown in Figure 2. According to the statistical analysis of coal mine accidents, roof fall accidents are frequent and occur easily, and the roof is still one of the important disaster affecting the safety of Guizhou coal mines. With the increase in coal mining intensity and depth, coal mine disaster control in Guizhou Province will also develop in the direction of strengthening roof disaster prevention and control [6-11].

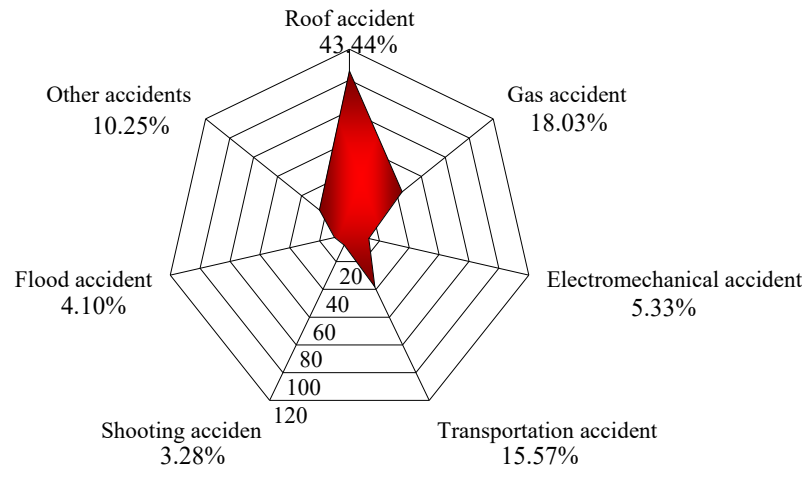

Figure 2. Statistics of coal mine accidents in Guizhou.

Before 2001, timber support was used basically in the coal mine roadway support in Guizhou Province. In 2007, the first support technology reform was carried out, using section steel instead of wood support. In 2009, bolt support was used in some coal mines, realizing the transformation from passive support to active support. However, so far, the proportion of bolt support is low (less than $30 \%$ ), and for complex and difficult roadways, such as in Guizhou mining area, for a large number of complex roof conditions, shed support was used in the roadway only basically. Practice has proved that as passive support, shed support cannot effectively restrain the large deformation of composite roof, the support and maintenance costs are high, and roof fall accidents occur frequently, which seriously threaten the safety production of the mine [12-16]. Therefore, to carry out research on the stability mechanism of roadway surrounding rock under the condition of composite roof, a scientific and reasonable mechanical structure model was established, and the adaptability of bolt support technology was theoretically explored under this condition, which is a useful attempt to promote the development of roadway excavation technology, with important theoretical value and practical significance.

At present, the theoretical models of composite roof are mainly divided into the following three categories [17-22]: (1) taking the span of the broken arch of composite roof drift outward as the fixed support end of composite roof rock beam; (2) taking the intersection of the roof and the two sides of composite roof roadway as the fixed support end of composite roof rock beam; (3) the roof is regarded as an elastic beam and solved by material mechanics or elasticity. However, the composite roof is generally deep beam, so it needs to be improved to treat the composite roof as a general elastic beam, while the composite roof is regarded as an infinite plate, which is more in line with the layered development characteristics of the composite roof. Considering that the rock contains defects and natural joint fissures, it is more suitable to study the composite roof as an elastic damage body. 


\section{Mechanical Structure Model of Composite Roof}

The composite roof is composed of weak coal and rock stratigraphy with small thickness, developed bedding, joints and fissures, and low strength. The cohesive stress between each rock stratum is weak or even non-cohesive. Under the action of concentrated stress caused by mining, shear failure is easy to occur. Each layer moves horizontally along the damaged structural plane, and the relative dislocation area is increasing, as is the longitudinal bending displacement of each layer. When the deflection reaches the limit span, the bending tensile failure will occur. Because the length of the roadway with composite roof is much larger than the width of the roadway, the length of the compound roof can be regarded as infinite. After the roadway with composite roof is excavated, under the action of overlying strata load $\gamma \cdot h$, the composite roof has different degrees of damage, and the bearing capacity decreases. Therefore, the damage problem of infinite long plate must be considered. The mechanical structure model of the composite roof is established as shown in Figure 3. The composite roof is composed of $m$ layers weak alternating rock, numbered $n_{1}, n_{2}, n_{3}, \ldots \ldots, n_{\mathrm{m}-1}, n_{\mathrm{m}}$, with the thickness represented as $h_{1}, h_{2}, h_{3}, \ldots \ldots$, $h_{\mathrm{m}-1}, h_{\mathrm{m}}$, respectively. The width of roadway is $a$, the height is $b$, the damage parameter is $D$, and the total thickness of composite roof is $h$.

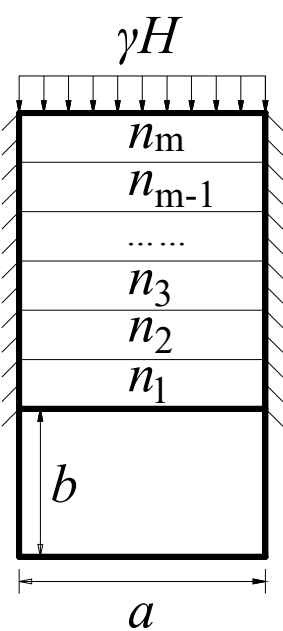

Figure 3. Mechanical structure model of composite roof.

In order to judge whether the composite roof of the coal roadway is separated or not, to solve the separation value of composite roof and analyze the stability of composite roof, the following studies are carried out: (1) the establishment of composite roof damage model; (2) considering the damage of composite roof, the separation judgment of each layer of composite roof, the solution of separation value and the law of stress distribution.

\section{Damage Model of Composite Roof Based on Weibull Distribution}

Rock has experienced a long period of geological process in the Earth's crust, and the structural failure has always been the key to the underground engineering design. The failure of the structure will not happen suddenly, but is the result of damage accumulation. The expansion of damages such as cracks, small folds, and small faults results in a continuous decrease in the strength of the rock mass structure, and eventually leads to loss of bearing capacity. Taking the elastic modulus as the damage index, the damage constitutive equation of the composite roof is as follows.

$$
\sigma=E(1-D) \varepsilon
$$

It is assumed that the composite roof rock mass is divided into several micro-elements with different defects, the micro-elements are assumed as follows:

(1). The micro-elements conform to the generalized Hooke's law. 
(2). The micro-element failure is in accordance with Mises yield criterion.

Weibull distribution is one of the commonly used distributions in reliability systems. In the study of rock damage problems, many random variables obey its distribution. It is assumed that the one-dimensional strength of micro-element conforms to Weibull statistical distribution law.

$$
\varphi(\varepsilon)=\left\{\begin{array}{l}
0, \varepsilon>0 \\
\frac{t}{\varepsilon_{0}}\left(\frac{\varepsilon}{\varepsilon_{0}}\right)^{t-1} \exp \left[-\left(\frac{\varepsilon}{\varepsilon_{0}}\right)^{t}\right], \varepsilon>0
\end{array}\right.
$$

where: $t$ is the morphological parameter; $\varepsilon_{0}$ is the scale parameter; $\varepsilon$ is the axial strain of rock micro-element; and $\varphi(\varepsilon)$ is the failure probability of micro-element when the axial strain of rock micro-element is $\varepsilon$.

The force acting on the micro-element is shown in Figure 4, which conforms to the generalized Hooke's law of linear elasticity.

$$
\left\{\begin{array}{l}
\sigma_{1}=(\lambda+2 \mu) \varepsilon_{1}+\lambda \varepsilon_{2}+\lambda \varepsilon_{3} \\
\sigma_{2}=(\lambda+2 \mu) \varepsilon_{2}+\lambda \varepsilon_{1}+\lambda \varepsilon_{3} \\
\sigma_{3}=(\lambda+2 \mu) \varepsilon_{3}+\lambda \varepsilon_{1}+\lambda \varepsilon_{2}
\end{array}\right.
$$

Among them:

$$
\left\{\begin{array}{l}
\lambda=\frac{E v}{(1+v)(1-2 v)} \\
\mu=\frac{E}{2(1+v)}
\end{array}\right.
$$
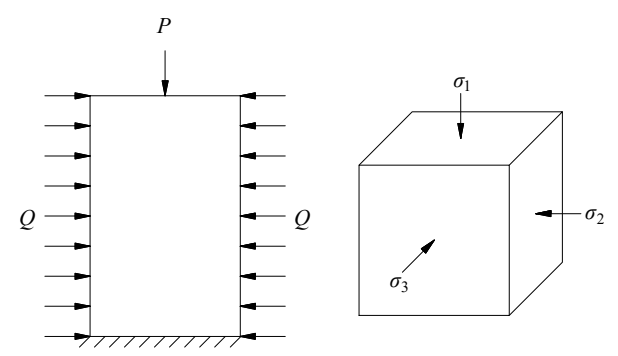

Figure 4. Schematic Diagram of Rock Sample Compression and Micro Element Stress.

In the formula: $\sigma_{1}, \sigma_{2}, \sigma_{3}, \varepsilon_{1}, \varepsilon_{2}$, and $\varepsilon_{3}$ are the three principal stresses and principal strains of the micro-element; $\lambda$ and $\mu$ are Lame constants; $E$ is the micro-element elastic model; $v$ is the Poisson's ratio.

When $\sigma_{2}=\sigma_{3}$, according to Equations (3) and (4), let $v=0.25$ to obtain:

$$
\varepsilon_{1}=\frac{\sigma_{1}}{E}-\frac{\sigma_{3}}{2 E}
$$

Because the micro-element failure is in accordance with Mises yield criterion:

$$
\left(\sigma_{1}-\sigma_{2}\right)^{2}+\left(\sigma_{1}-\sigma_{2}\right)^{2}+\left(\sigma_{3}-\sigma_{1}\right)^{2}=2 \sigma_{0}^{2}
$$

In the formula, $\sigma_{0}$ is the uniaxial compressive strength of the rock micro-element. When $\sigma_{2}=\sigma_{3}$, substitute Equation (6) to obtain:

$$
\left|\sigma_{1}-\sigma_{3}\right|=\sigma_{0}
$$

From Equations (5) and (7), the principal strain $\varepsilon_{1}$ at the time of failure of the microelement under the three-dimensional condition can be obtained:

$$
\varepsilon_{1}=\frac{\sigma_{0}}{E}+\frac{\sigma_{3}}{2 E}
$$


Because the one-dimensional strength of micro-element conforms to the Weibull statistical distribution law, when the micro-element yields failure:

$$
\varepsilon=\varepsilon_{1}-\frac{\sigma_{3}}{2 E}
$$

According to continuum damage mechanics, the damage parameter $D$ can be defined as the ratio of damage area to material area without damage:

$$
D=\frac{S}{S_{m}}=\int_{0}^{\varepsilon} \varphi(\varepsilon) d \varepsilon
$$

Substitute Formulas (2) and (9) into Formula (10) to obtain:

$$
D=\int_{0}^{\varepsilon_{1}-\frac{\sigma_{3}}{2 E}} \frac{t}{\varepsilon_{0}}\left(\frac{\varepsilon}{\varepsilon_{0}}\right)^{t-1} \exp \left[-\left(\frac{\varepsilon}{\varepsilon_{0}}\right)^{t}\right] d \varepsilon
$$

The damage parameter $D$ is obtained by integrating Equation (11):

$$
D=1-\exp ^{-\left(\frac{\varepsilon_{1}-\frac{\sigma_{3}}{2 E}}{\varepsilon 0}\right)^{t}}
$$

For the composite roof, the principal strain is the ratio of the subsidence $z_{0}$ of the composite roof to the thickness $h$ of the composite roof, namely:

$$
\varepsilon_{1}=\frac{z_{0}}{h}
$$

Substitute Equation (12) to obtain:

$$
D=1-\exp ^{-\left(\frac{z_{0}-\frac{\sigma_{3}}{h} \varepsilon_{0}}{\varepsilon_{0}}\right)^{t}}
$$

The coal elastic modulus $E=0.8 \mathrm{GPa}$, the composite roof confining pressure $\sigma_{3}=2 \mathrm{MPa}$, the Weibull scale parameter $\varepsilon_{0}=0.5$. The relationship between damage parameter $D$ and principal strain $\varepsilon_{1}$ of composite roof with Weibull shape parameter $t$ of $1,2,3$ and 4 is shown in Figure 5.

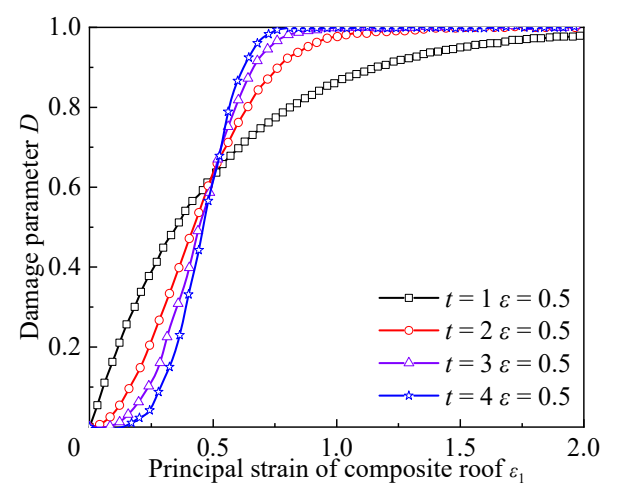

Figure 5. Relationship between damage parameters and principal strain of composite roof under different Weibull shape parameters.

It can be seen from Figure 5 that the Weibull shape parameter $t$ is the most important parameter. When the Weibull shape parameter $t$ is 1 , the damage parameter $D$ of the composite roof increases exponentially with the increase in the principal strain, and is basically stable when the principal strain is 2 ; when the shape parameter $t$ is greater than 1 , 
with the increase in the principal strain, the damage parameter $D$ of the composite roof first increases rapidly, then slowly increases, and finally gradually tends to be stable. When it changes to 0.5 , the damage parameter $D$ of composite roof is basically the same under different shape parameters $t$. With the increase in principal strain, the larger the shape parameter is, the greater the damage parameter $D$ of composite roof is. With the decrease in principal strain, the smaller the shape parameter is, the greater the damage parameter $D$ of composite roof is.

Take the elastic modulus $E$ of coal body as $0.8 \mathrm{GPa}$, the confining pressure $\sigma_{3}$ of composite roof is $2 \mathrm{MPa}$, the Weibull shape parameter $t$ is 2 . The relationship between damage parameter $D$ and principal strain $\varepsilon_{1}$ of composite roof with the Weibull scale parameter $\varepsilon_{0}$ of $0.1,0.3,0.5$ and 0.7, respectively, are shown in Figure 6.

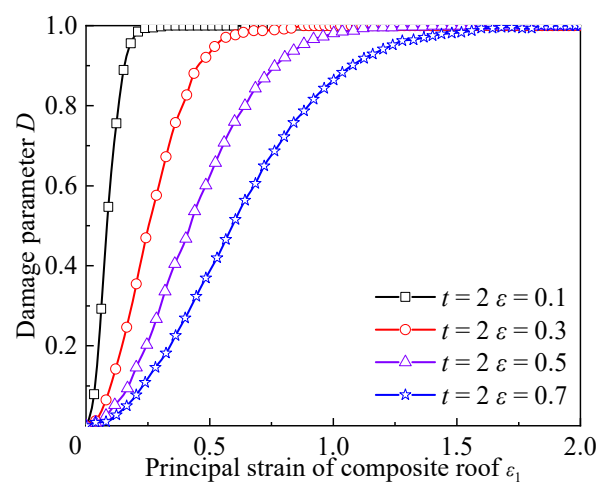

Figure 6. Relationship between damage parameters and principal strain of composite roof under different Weibull scale parameters.

It can be seen from Figure 6 that when the Weibull shape parameter $t$ is 2, the damage parameter $D$ increases exponentially with the increase in principal strain under different Weibull scale conditions. The scale parameter $\varepsilon_{0}$ does not change the growth trend of damage parameter $D$. However, the larger the scale parameter $\varepsilon_{0}$ is, the faster the damage parameter $D$ of composite roof increases with the increase in principal strain.

\section{Stability of Composite Roof and Its Influencing Factors}

\subsection{Deflection and Stress Distribution of Composite Roof}

The mechanical model of composite roof is shown in Figure 7. The upper part of composite roof $n_{1}$ bears a vertical downward distributed force, the size is $q=\gamma \cdot h$, and there is horizontal thrust at both ends, the size is $p$.
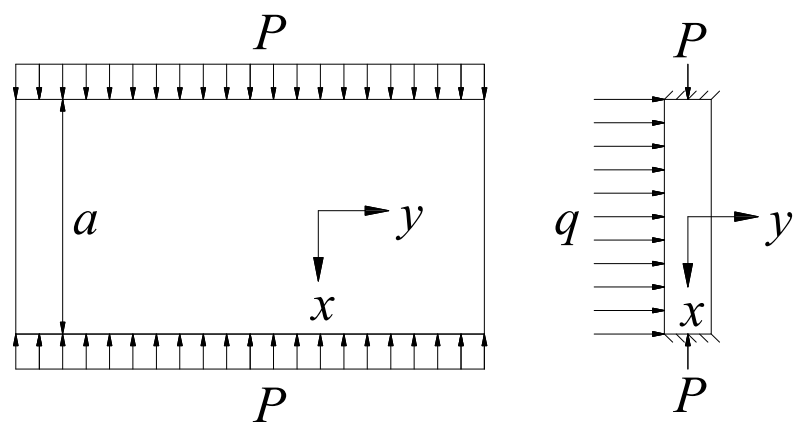

Figure 7. Mechanical model of composite roof strata.

Under the stress of distributed load $q$, the elastic surface differential equation of layer $n_{1}$ :

$$
Q_{1} \nabla^{4} w_{1}=q, Q_{1}=E_{1} h_{1}^{3} /\left(12\left(1-\mu_{1}^{2}\right)\right)
$$


In the equation: $w_{1}$ is the deflection of layer $n_{1} ; Q_{1}$ is the flexural rigidity of layer $n_{1} ; q$ is distributed load; $E_{1}$ is elastic modulus of layer $n_{1} ; h_{1}$ is the thickness of layer $n_{1}, \mathrm{~m} ; \mu_{1}$ is Poisson ration of layer $n_{1}$.

Generally, $q$ is the function of $x$, and to facilitate analysis, make $q$ a constant. Use the boundary condition of two edges fixed to solve deflection expression:

$$
w_{1}=q a^{4}\left(1-8 x^{2} / a^{2}+16 x_{4} / a^{4}\right) /\left(384 Q_{1}\right)
$$

When $x=0, w_{1}$ achieves the maximum:

$$
w_{1 \max }=q a^{4} /\left(384 Q_{1}\right)
$$

Stress caused by the horizontal force $p$ :

$$
\sigma_{x}=P / h_{1}, \sigma_{y}=\mu_{1} P / h_{1}
$$

Stress of the layer $n_{1}$ :

$$
\begin{aligned}
& \sigma_{x}=q z a^{2}\left(12 x^{2} / a^{2}-1\right) / 2 h_{1}{ }^{3}+P / h_{1}, \sigma_{y}=q z a^{2}\left(12 x^{2} / a^{2}-1\right) / 2 h_{1}{ }^{3}+\mu_{1} P / h_{1} \\
& \sigma_{z}=2 q\left(1 / 2-z / h_{1}\right)^{2}\left(1+z / h_{1}\right), \tau_{z x}=6 q x\left(h_{1}{ }^{2} / 4-z^{2}\right) / h_{1}{ }^{3}
\end{aligned}
$$

Regard the infinite plate as thin plate, $\tau_{x y}$ and $\tau_{y z}$ are both 0 .

\subsection{Determination of Separation and Instability of Composite Roof}

Considering the damage of composite roof, the expression of layer $n_{1}$ deflection is as follows:

$$
w_{1}=12 q a^{4}\left(1-\mu_{1}^{2}\right)\left(1-8 x^{2} / a^{2}+16 x_{4} / a^{4}\right) / 384 E_{1} h_{1}^{3} \exp ^{-\left(\frac{z_{0}}{h}-\frac{\sigma_{3}}{2 E_{1}}\right)^{t}}
$$

For layer $n_{2}$, if its deflection is less than layer $n_{1}$, the deflection expression is as follows:

$$
w_{2}=12 q a^{4}\left(1-\mu_{2}^{2}\right)\left(1-8 x^{2} / a^{2}+16 x_{4} / a^{4}\right) / 384 E_{2} h_{2}^{3} \exp ^{-\left(\frac{z_{0}-\frac{\sigma_{3}}{2 E_{2}}}{\varepsilon_{0}}{ }^{t}\right.}
$$

The separation values of layer $n_{2}$ and layer $n_{1}$ are:

$$
l_{12}=w_{1}-w_{2}
$$

If the layer $n_{2}$ deflection is greater than layer $n_{1}$, there is no separation. Then, the deflection expression of layer $n_{2}$ and layer $n_{1}$ composite plate is:

$$
w_{12}=12 q a^{4}\left(1-\mu_{12}{ }^{2}\right)\left(1-8 x^{2} / a^{2}+16 x_{4} / a^{4}\right) / 384 E_{12} h_{1}^{3} \exp ^{-\left(\frac{\frac{z_{0}}{h}-\frac{\sigma_{3}}{2 E_{12}}}{\varepsilon_{0}}\right)^{t}}
$$

Obviously, the stress of the layer $n_{1}$ at the fixed support end is the largest. According to the Tresca yield criterion, considering that the stress $\sigma_{x}$ is far greater than that of $\sigma_{z}$ and $\sigma_{z x}$, then critical load $q$ at yield of the layer $n_{1}$ :

$$
q_{0}=\left(4 \tau_{1} h_{1}^{2}-2 p h_{1}\right) / a^{2},
$$

where, $\tau_{1}$ is the shear strength of layer $n_{1}$.

\subsection{Influencing Factors of Composite Roof Stability}

Xiaotun coal mine is located in Bijie City, Guizhou Province, China. Working face 1603 is the first mining face in the mine field, with an average buried depth of $260 \mathrm{~m}$, strike 
length of $988 \mathrm{~m}$ and width of $150 \mathrm{~m}$. The transport roadway of 1603 working face was driven along the coal seam floor with a cross-section of $4.3 \mathrm{~m} \times 2.7 \mathrm{~m}$ (width $\times$ height). During the excavation of the roadway, the roof subsidence was severe, and a serious roof fall accident occurred, which seriously threatened the safety of mine production. The coal seam of 1603 working face is No. 6 coal seam of Longtan Formation, with an average thickness of $2.41 \mathrm{~m}$. The upper composite roof consists of mudstone, No. 5 coal seam and its gangue, whose specific composition was shown in Table 1. In order to explore the causes of roof fall accident in 1603 working face, it is necessary to study the stability of the upper composite roof. Therefore, taking mudstone with the thickness of $0.6 \mathrm{~m}$ as the research object, the influence of the width of coal roadway with composite roof $a$, the load of overlying strata $q$, elastic modulus $E$, Poisson's ratio $\mu$, shape parameter $t$ and scale parameter $\varepsilon_{0}$ on the bending subsidence and separation of composite roof were analyzed.

Table 1. Composition and parameters of composite roof.

\begin{tabular}{cccccc}
\hline Roof Type & Serial Number & Lithology & Thickness/m & $\begin{array}{c}\text { Elastic } \\
\text { Modulus/MPa }\end{array}$ & $\begin{array}{c}\text { Poisson's } \\
\text { Ratio }\end{array}$ \\
\hline & 1 & Mudstone & 0.60 & 926 & 0.32 \\
& 2 & Upper layer of & 0.26 & 445 & 0.33 \\
Composite roof & 3 & 5\# coal seam & 0.68 & 1635 & 0.32 \\
& 4 & Tonsteins & 0.20 & 0.40 & 1938 \\
Main roof & 5 & 5\# coal seam & Tonsteins & 0.22 & 445 \\
\hline
\end{tabular}

The main strain of composite roof is taken as $\varepsilon_{1}=0.2$, confining pressure $\sigma_{3}=2 \mathrm{MPa}$, shape parameter $t=2$, scale parameter $\varepsilon_{0}=0.5$, overburden load $q=6.5 \mathrm{MPa}$, roadway width $a=4.3 \mathrm{~m}$, and other parameters are shown in Table 1 .

(1). Roadway width

The influence of roadway width on the deflection of mudstone with the thickness of $0.6 \mathrm{~m}$ in composite roof is shown in Figure 8 . The roadway widths are $4.0 \mathrm{~m}, 4.3 \mathrm{~m}, 4.6 \mathrm{~m}$, and $4.9 \mathrm{~m}$, respectively.

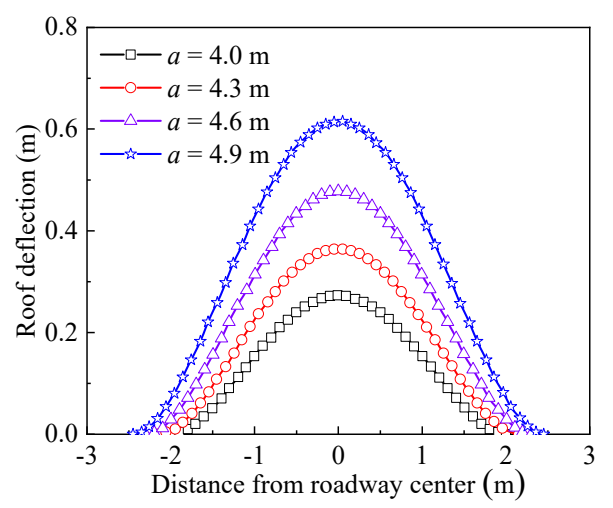

Figure 8. Relationship between composite roof deflection and roadway width.

It can be seen from Figure 8 that in the middle of the composite roof, the deflection of mudstone stratification reaches the maximum. With the increase in roadway width, the maximum deflection of mudstone layer increases, and the amplitude increases. From the middle part of the composite roof to the end of two fixed supports, the deflection of mudstone layer decreases, but the decreasing range increases. Therefore, the increase in 
roadway section will significantly increase the subsidence of mudstone stratification, and the stability of composite roof will decrease sharply.

(2). Overlying strata load

The load of overlying strata is directly proportional to the buried depth of roadway. The buried depth of roadway is taken as $60 \mathrm{~m}, 260 \mathrm{~m}, 460 \mathrm{~m}, 660 \mathrm{~m}$, and $860 \mathrm{~m}$ respectively. The influence of roadway buried depth on the deflection of mudstone with the thickness of $0.6 \mathrm{~m}$ in composite roof is shown in Figure 9.

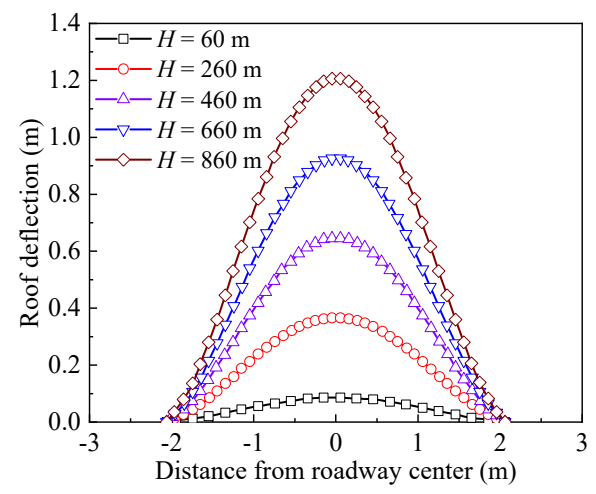

Figure 9. Relation between deflection of composite roof and buried depth of roadway.

As shown in Figure 9, the maximum deflection of mudstone stratification is $0.084 \mathrm{~m}$, $0.365 \mathrm{~m}, 0.646 \mathrm{~m}, 0.927 \mathrm{~m}$, and $1.208 \mathrm{~m}$ when the roadway buried depth is $60 \mathrm{~m}, 260 \mathrm{~m}$, $460 \mathrm{~m}, 660 \mathrm{~m}$, and $860 \mathrm{~m}$, respectively. The maximum deflection of mudstone stratification increases linearly with the increase in roadway buried depth, because the vertical and horizontal stress at rest, which grow in depth, are important for maximum deflection. When the buried depth is shallow, the subsidence of mudstone is small, and the roadway is easy to maintain. However, after deep mining, the mudstone deformation is serious, and the roof is easily damaged.

(3). Elastic modulus

The elastic modulus of mudstone stratification is $800 \mathrm{MPa}, 900 \mathrm{MPa}, 1000 \mathrm{MPa}$ and $1100 \mathrm{MPa}$, respectively. The influence of mudstone strength on the deflection of mudstone with the thickness of $0.6 \mathrm{~m}$ in composite roof is shown in Figure 10.

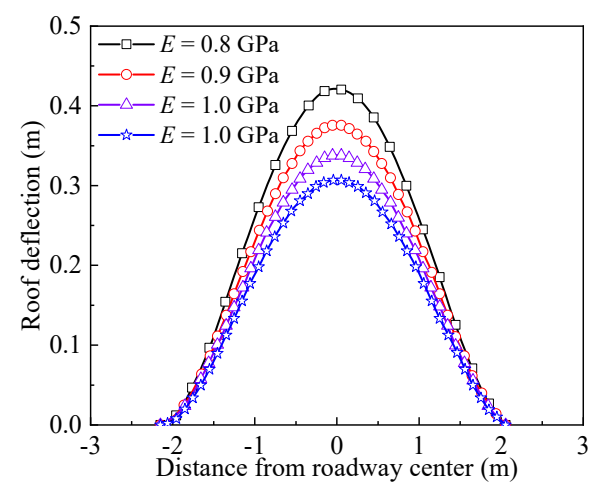

Figure 10. Relationship between composite roof deflection and rock strength.It can be seen from Figure 10 that with the increase of rock elastic modulus, the maximum deflection of mudstone stratification is accelerating and decreasing. Therefore, when the composite roof remains intact, the bearing capacity is strong, but the composite roof is damaged and its bearing capacity decreases sharply.

(4). Shape parameter

The shape parameters $t$ are taken as 1, 2, 3 and 4 respectively. The influence of shape parameter on the deflection of $0.6 \mathrm{~m}$ mudstone of composite roof is shown in Figure 11. 


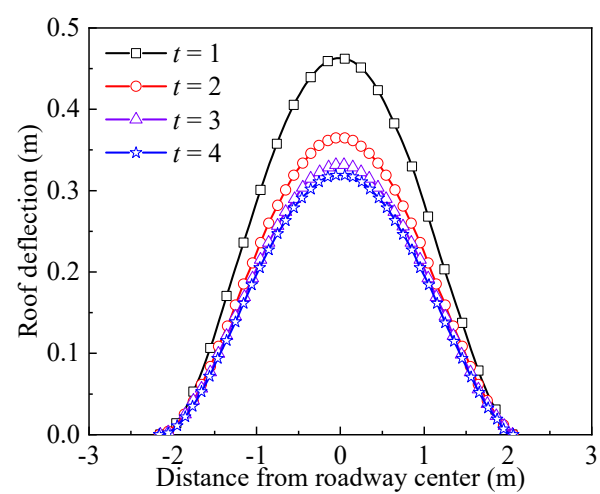

Figure 11. Relationship between composite roof deflection and shape parameter.

It can be seen from Figure 11 that when the shape parameter $t=1$, the maximum deflection of mudstone stratification is $0.464 \mathrm{~m}$. When the shape parameter $t$ increases to 2, the maximum deflection of mudstone stratification decreases sharply to $0.365 \mathrm{~m}$. Then, with the increase of shape parameter, the reduction range of maximum deflection of mudstone stratification becomes smaller and smaller. When the shape parameter $t$ increases from 3 to 4 , the maximum deflection of mudstone stratification decreases only $12 \mathrm{~mm}$.

(5). Scale parameter

The scale parameters $\varepsilon_{0}$ are taken as $0.3,0.4,0.5$ and 0.6 , respectively. The influence of scale parameter on the deflection of mudstone with the thickness of $0.6 \mathrm{~m}$ in composite roof is shown in Figure 12

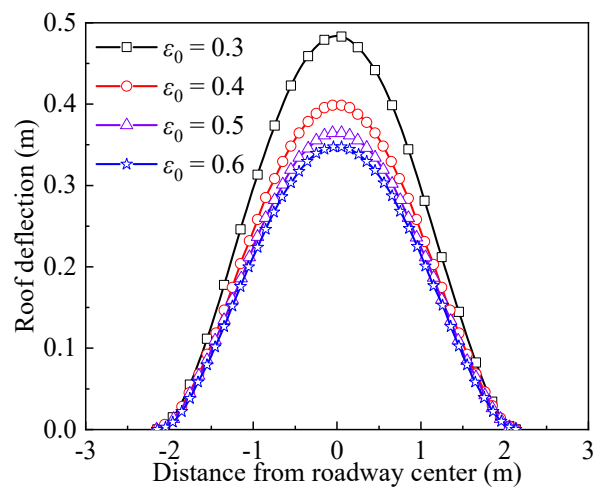

Figure 12. Relationship between composite roof deflection and scale parameter.

It can be seen from Figure 12 that when the scale parameter $\varepsilon_{0}=0.3$, the maximum deflection of mudstone stratification is $0.484 \mathrm{~m}$; when the scale parameter increases to 0.4 , the maximum deflection of mudstone stratification decreases sharply to $0.399 \mathrm{~m}$; with the continuous increase in scale parameter, the maximum deflection of mudstone stratification decreases more and more, and when the scale parameter increases from 0.5 to 0.6 , the maximum deflection of mudstone stratification only decreases by $17 \mathrm{~mm}$. The effect of the scale parameter $\varepsilon_{0}$ on the deflection of mudstone is basically consistent with the shape parameter $t$.

\section{Influence of Bolt Support on Stability of Composite Roof}

Bolt is a supporting form with both supporting and reinforcing functions: on the one hand, the bolt exerts confining pressure on the surrounding rock through radial anchoring force (pre tightening force and adhesive anchoring force), which makes the coal body change from one-dimensional or two-dimensional stress state to three-dimensional 
stress state, and enhances the stability of coal body; on the other hand, bolt improves the mechanical parameters of anchor body through tangential anchoring force [23-26].

After the bolt support is used in the roadway with composite roof, the original separation is eliminated in the anchorage zone, and the composite roof forms a complete composite plate structure, and its elastic modulus and Poisson's ratio are:

$$
\begin{aligned}
E & =\frac{E_{1} h_{1}+E_{2} h_{2}+E_{3} h_{3}+E_{4} h_{4}+E_{5} h_{5}+E_{6} h_{6}}{h_{1}+h_{2}+h_{3}+h_{4}+h_{5}+h_{6}} \\
& =\frac{926 \times 0.6+445 \times 0.26+1635 \times 0.68+445 \times 0.2+1938 \times 0.4+445 \times 0.22}{0.6+0.26+0.68+0.2+0.4+0.22} \\
& =1163.22 \mathrm{Mpa} \\
E & =\frac{\mu_{1} h_{1}+\mu_{2} h_{2}+\mu_{3} h_{3}+\mu_{4} h_{4}+\mu_{5} h_{5}+\mu_{6} h_{6}}{h_{1}+h_{2}+h_{3}+h_{4}+h_{5}+h_{6}} \\
& =\frac{0.32 \times 0.6+0.33 \times 0.26+0.32 \times 0.68+0.33 \times 0.2+0.32 \times 0.4+0.33 \times 0.22}{0.6+0.26+0.68+0.2+0.4+0.22} \\
& =0.323
\end{aligned}
$$

The influence of bolt support on composite roof separation is shown in Figure 13. It can be seen from Figure 13 that after bolting, the maximum separation of composite roof is $2.7 \mathrm{~mm}$ when damage is considered; when damage is not considered, the separation between composite roof and basic roof is $2.3 \mathrm{~mm}$, which can be approximately considered that there is no separation of composite roof. Therefore, bolt support effectively reduces the separation between the composite roof and the basic roof, improves the overall strength and stiffness of the composite roof, greatly enhances the stability of the composite roof, and thus ensures the stability of the surrounding rock of the roadway. Therefore, for the surrounding rock control of roadway with composite roof, the active support technology with bolt as the core should be adopted. At the same time, the bolt support system should choose the bolt with high strength and stiffness and a certain yield performance to give the composite roof a certain deformation space, which can not only ensure the stability of the composite roof structure, but also effectively prevent the damage of the bolt support system.

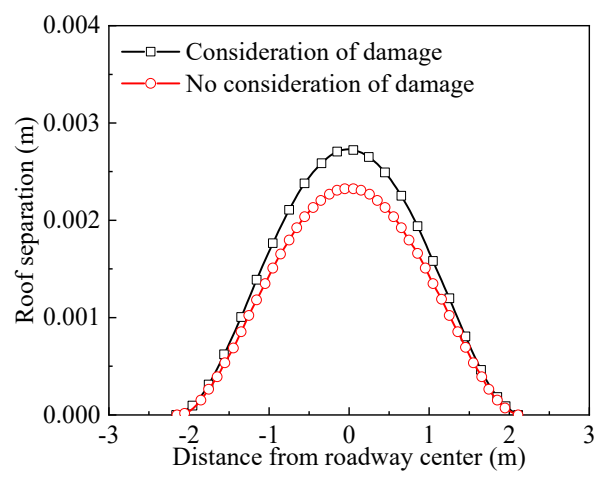

Figure 13. Influence of bolt support on composite roof separation.

\section{Conclusions}

(1) Based on Weibull statistical distribution, generalized Hooke's law and Mises yield criterion, the expression of damage parameters of composite roof is obtained. The influence of Weibull shape parameters and scale parameters on damage parameters is discussed. When the shape parameter is 1 , the damage parameter of composite roof increases exponentially with the increase in principal strain. When the shape parameter is greater than 1 , the damage parameter of composite roof increases exponentially with the increase in principal strain, when the principal strain is greater than 0.5 , the larger the shape parameter is, the larger the damage parameter is. When the principal strain is less than 0.5 , the smaller the shape parameter is, the larger the damage parameter is. Under the condition of different scale parameters, with the increase in principal strain, the growth rate of damage parameter of composite roof is greater and the stability is faster. 
(2) Based on the theory of infinite length plate, the expressions of deflection and separation of each layer of composite roof are derived, and the critical load expression of each layer is given. The influence law of the width of coal roadway, the load of overlying strata, elastic modulus, shape parameters and scale parameters on the stability of composite roof is discussed. The maximum subsidence and separation of each layer of composite roof is directly proportional to the fourth power of roadway width. The large section of coal roadway with composite roof significantly increases the subsidence and separation of each layer, and the stability of composite roof decreases sharply; the load of overlying strata is proportional to the buried depth of coal roadway with composite roof, and the maximum deflection of each layer increases linearly with the increase in buried depth of coal roadway with composite roof. When the buried depth is shallow, the subsidence of mudstone is small and easy to maintain. However, after deep mining, the deformation of each layer is serious, and it is easy to lose stability and cause failure; with the increase in elastic modulus, the maximum deflection of each layer decreases continuously, and the reduction range decreases continuously; when the shape parameter increases from 1 to 2 , the maximum deflection of each layer decreases sharply, and then with the increase in shape parameters, the decrease in maximum deflection of each layer becomes smaller and smaller. The larger the shape parameter is, the stronger the stability of composite roof is; the influence of scale parameters on the stability of each layer is consistent with the shape parameters.

(3) Bolt is a supporting form with both supporting and reinforcing functions. After using bolt support, the separation between layers of composite roof is effectively reduced, and the stability of composite roof is greatly enhanced. For the surrounding rock control of roadway with composite roof, the active support technology with bolt as the core should be adopted.

Author Contributions: J.L. conceived and designed the research; Y.P. and X.Z. performed the field tests; L.Z. and D.C. provided theoretical guidance in the research process; Y.Y. analyzed the data and wrote the paper. All authors have read and agreed to the published version of the manuscript.

Funding: This work was supported by the National Natural Science Foundation of China (grant numbers 51904296 and 52074240), the Outstanding Backbone Teachers of "Innovation Project" of University in Jiangsu Province, China, in 2020, Young academic leaders of "Innovation Project" of University in Jiangsu Province, China, in 2021 and Major Projects of Natural Science Foundation of Universities in Jiangsu Province, China (grant numbers 20KJA560001). The sources of this support are gratefully acknowledged.

Data Availability Statement: The data presented in this study are available on request from the corresponding author.

Acknowledgments: This research was supported by Jiangsu high performance structural materials and safety control engineering laboratory, and thank three reviewers for their vital comments.

Conflicts of Interest: The authors declare no conflict of interest.

\section{References}

1. Jun, X.; Liang, Y.P.; Zou, Q.L.; Li, L.; Li, X.L. Elimination of coal and gas outburst risk of low-permeability coal seam using high-pressure water jet slotting technology: A case study in Shihuatian Coal Mine in Guizhou Province, China. Energy Sci. Eng. 2019, 7, 1394-1404. [CrossRef]

2. Teng, J.W.; Qiao, Y.H.; Song, P.H. Analysis of exploration, potential reserves and high efficient utilization of coal in China. Chin. J. Geophys. 2016, 59, 4633-4653.

3. Wang, Q.; Song, X.X.; Liu, Y. China's coal consumption in a globalizing world: Insights from Multi-Regional Input-Output and structural decomposition analysis. Sci. Total Environ. 2020, 711, 134790. [CrossRef]

4. Yang, Y.X.; Zheng, X.Y.; Sun, Z. Coal Resource Security Assessment in China: A Study Using Entropy-Weight-Based TOPSIS and BP Neural Network. Sustainability 2020, 12, 2294. [CrossRef]

5. Zhang, H.L.; Shen, L.; Zhong, S.; Elshkaki, A. Coal resource and industrial structure nexus in energy-rich area: The case of the contiguous area of Shanxi and Shaanxi Provinces, and Inner Mongolia Autonomous Region of China. Resour. Policy 2020, 66, 101646. [CrossRef] 
6. Hu, X.S.; Wu, Z.Z.; Wang, R.J.; Duoc, Y.Q. Statistical analysis of coal mine accidents in China from 2005-2013. Oper. Environ. Mine Health Saf. Prac. Innov. 2016, 527-530, 2213-2221.

7. Jiao, Y.Y.; Wang, Z.H.; Wang, X.Z.; Adoko, A.C.; Yang, Z.X. Stability assessment of an ancient landslide crossed by two coal mine tunnels. Eng. Geol. 2013, 159, 36-44. [CrossRef]

8. Li, Q.S.; He, X.; Wu, J.H.; Ma, S. Investigation on coal seam distribution and gas occurrence law in Guizhou, China. Energy Explor Exploit. 2018, 36, 1310-1334. [CrossRef]

9. Xu, Y.L.; Pan, K.R.; Zhang, H. Investigation of key techniques on floor roadway support under the impacts of superimposed mining: Theoretical analysis and field study. Environ. Earth Sci. 2019, 78, 1-14. [CrossRef]

10. Yan, H.K.; He, H.F. The Analysis of Coal Mine Safety Production Risk in Guizhou Province. Chin. Perspect. Risk Anal. Crisis Response 2010, 13, 1084-1089.

11. Zhang, Z.Z.; Deng, M.; Bai, J.B.; Yu, X.Y.; Wu, Q.H.; Jiang, L.S. Strain energy evolution and conversion under triaxial unloading confining pressure tests due to gob-side entry retained. Int. J. Rock Mech. Min. Sci. 2020, 126, 10. [CrossRef]

12. Chang, J.C.; He, K.; Yin, Z.Q.; Li, W.F.; Li, S.H.; Pang, D.D. Study on the Instability Characteristics and Bolt Support in Deep Mining Roadways Based on the Surrounding Rock Stability Index: Example of Pansan Coal Mine. Adv. Civ. Eng. 2020, 2020, 8855335. [CrossRef]

13. Zhang, J.P.; Liu, L.M.; Shao, J.; Li, Q.H. Mechanical Properties and Application of Right-Hand Rolling-Thread Steel Bolt in Deep and High-Stress Roadway. Metals 2019, 9, 346. [CrossRef]

14. Hao, X.J.; Wang, S.H.; Jin, D.X.; Ren, B.; Zhang, X.Y.; Qiu, K.L.; Fan, Y.J. Instability Process of Crack Propagation and Tunnel Failure Affected by Cross-Sectional Geometry of an Underground Tunnel. Adv. Civ. Eng. 2019, 2019, 17. [CrossRef]

15. Zheng, X.G.; Feng, X.W.; Zhang, N.; Gong, L.Y.; Hua, J.B. Serial decoupling of bolts in coal mine roadway supports. Arab. J. Geosci. 2015, 8, 6709-6722. [CrossRef]

16. Kang, H.; Wu, Y.; Gao, F.; Lin, J.; Jiang, P. Fracture characteristics in rock bolts in underground coal mine roadways. Int. J. Rock Mech. Min. Sci. 2013, 62, 105-112. [CrossRef]

17. Zhang, Y.; Xu, H.C.; Song, P.; Sun, X.M.; He, M.C.; Guo, Z.B. Stress Evolution Law of Surrounding Rock with Gob-Side Entry Retaining by Roof Cutting and Pressure Release in Composite Roof. Adv. Mater. Sci. Eng. 2020, 2020, 1961680. [CrossRef]

18. Yu, Y.; Wang, X.Y.; Bai, J.B.; Zhang, L.Y.; Xia, H.C. Deformation Mechanism and Stability Control of Roadway Surrounding Rock with Compound Roof: Research and Applications. Energies 2020, 13, 1350. [CrossRef]

19. Pavlovic, A.; Sintoni, D.; Fragassa, C.; Minak, G. Multi-Objective Design Optimization of the Reinforced Composite Roof in a Solar Vehicle. Appl. Sci. 2020, 10, 2665. [CrossRef]

20. Xiong, X.Y.; Dai, J.; Wang, X. Comprehensive Analysis of Stability of Coal Seam Composite Roof Based on Analytic Hierarchy Process. Adv. Civ. Eng. 2019, 2019, 2042460. [CrossRef]

21. He, M.C.; Ma, X.G.; Yu, B. Analysis of Strata Behavior Process Characteristics of Gob-Side Entry Retaining with Roof Cutting and Pressure Releasing Based on Composite Roof Structure. Shock. Vib. 2019, 2019, 2380342. [CrossRef]

22. Li, C.E.; Duan, H.M.; Wang, D.Q. The Application of High Strength Anchor about Compound Roof Support about in Guantun Coal Mine. Adv. Mater. Res. 2013, 813, 281-283. [CrossRef]

23. Mandal, P.K.; Das, A.J.; Kumar, N.; Bhattacharjee, R.; Tewari, S.; Kushwaha, A. Assessment of roof convergence during driving roadways in underground coal mines by continuous miner. Int. J. Rock Mech. Min. Sci. 2018, 108, 169-178. [CrossRef]

24. Sneddon, C.; Manuel, S. Use of Recycled Drill Pipes for Soldier Piles and Anchored Walls for Roadway Embankment Reconstruction. Geotech. Front. 2017, 453-460. [CrossRef]

25. Kang, H.P.; Li, J.Z.; Yang, J.H.; Gao, F.Q. Investigation on the Influence of Abutment Pressure on the Stability of Rock Bolt Reinforced Roof Strata Through Physical and Numerical Modeling. Rock Mech. Rock Eng. 2017, 50, 387-401. [CrossRef]

26. Coggan, J.; Gao, F.Q.; Stead, D.; Elmo, D. Numerical modelling of the effects of weak immediate roof lithology on coal mine roadway stability. Int. J. Coal Geol. 2012, 90, 100-109. [CrossRef] 